\title{
Reseña bibliográfica de: García Prieto, E. (2018). Una corte en femenino. Servicio áulico y carrera cortesana en tiempos de Felipe II. Madrid: Marcial Pons. 310 pp.
}

Palabras clave: Ana de Austria; Felipe II; Estudios de corte; Historia de las Mujeres; Nueva historia política.

Keywords: Anna of Austria; Philip II; Court studies; Women's History; New political. history.

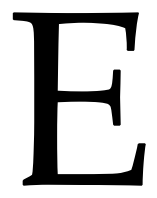

trabajo realizado por la doctora Elisa García Prieto, profesora de la Universidad Complutense de Madrid, representa un aporte relevante para conocer desde una nueva arista a la corte hispana durante el reinado de Felipe II. En este caso, se estudia la vida de las mujeres que integraron la casa de la reina consorte Ana de Austria, entendida como un espacio social dinámico y con una notable capacidad de adaptación a las diferentes coyunturas políticas y familiares. Este elemento resulta central, ya que el servicio doméstico regio tuvo que reconvertirse tras la muerte de la soberana en 1580, cuando Felipe II quedó viudo por cuarta y última vez. A partir de ello, tanto el espacio vacante que dejó, así como también sus servidores, fueron ocupados lentamente por el príncipe heredero (futuro Felipe III) y por las infantas Isabel y Catalina.

En términos historiográficos, estamos frente a un trabajo deudor de la nueva historia política, pero que no rehúye a realizar aportes a la historia social y cultural. Su marco está delimitado dentro de los llamados "estudios de corte", corriente que impulsó la revisión de postulados clásicos que habían hecho hincapié en la organización políticoinstitucional de los reinos de la Edad Moderna o en el absolutismo monárquico. Por el contrario, esta renovación tuvo el afán de estudiar el funcionamiento del gobierno y la gestión de las monarquías europeas, rescatando la figura del individuo ya no atado al corset institucional o al de la lucha de clases, sino enfocándose en el ejercicio del poder a través de las vías e instancias personales y extra institucionales, caracterizadas por el entroncamiento de redes de patronazgo y clientelismo. De esta manera, adquirieron nuevo protagonismo no solo la figura de los reyes, sino también la de sus distintos 
allegados: ministros, secretarios, embajadores, virreyes, gobernadores, príncipes de sangre, etc.

Si bien las nuevas preguntas que surgieron a partir de esta propuesta teórica y metodológica dieron fructíferos resultados para el estudio del caso español, aún quedaba pendiente una mirada desde la historia de las mujeres; por lo tanto, aquí radica la importancia del libro de García Prieto. Como muy bien se señala en el mismo, ya no se trata de estudiarlas solamente en función de su relación con el género masculino, sino también dentro de su condición específica. Con esto, se quiere subrayar el hecho de que una mujer que ocupaba un lugar en la corte (ya sea una reina, una camarera mayor o una dama de compañía) poseía un papel concreto que, simultáneamente, se veía atravesado no solo por lo que se esperaba que pudiera hacer, o sea por su condición femenina, sino también por sus propios intereses y condicionantes personalesfamiliares. Aquí se destacaban sus ansias de promoción económica y social, la obtención de mercedes regias, la conservación del honor y el estatus social, etc. Por lo tanto, el intrincado juego político y social restringido al "microcosmo femenino" nos resulta atractivo debido a que se presenta, en cierta medida, como una caja de resonancia del reinado de Felipe II a partir de 1570. Sin lugar a dudas, este aporte puede complementar los variados estudios biográficos y políticos del Rey Prudente, así como los de carácter general de su reinado, ya realizadas por Gregorio Marañón, Fernand Braudel, Geoffrey Parker, Henry Kamen, entre los autores modernos más destacados.

Para lograr una mejor comprensión de su obra, la autora la organizó en tres grandes partes. En primer lugar, reconstruyó el curso diacrónico y lineal de la constitución y desarrollo de la casa de la reina Ana, junto a la designación de sus principales oficiales, tanto masculinos como femeninos. Tras su muerte, se analizó la transformación del espacio doméstico a partir del papel que los infantes fueron adquiriendo allí, a quienes su padre les dio la misión de suplir la ausencia de su esposa, disponiendo de una parte de aquel servicio regio, hasta que sus respectivos casamientos y/o partidas de la corte española culminaron aquella etapa de sus vidas. De esta manera, la estructura palaciega vacante que había pertenecido a la última esposa de Felipe II no solo tuvo la función de brindarle servicio, sino también permitirles el aprendizaje a través de una primera experiencia de conducción de una casa real, cualidad crucial que debían desarrollar para ejercer como futuros soberanos de un reino.

En segundo lugar, la autora explicó la importancia de la casa de la reina, a partir de la caracterización de los siguientes aspectos: los diferentes espacios palatinos, la imagen que debía irradiar (entendida como un modelo de soberana y mujer católica), los conflictos y tensiones suscitadas entre los servidores y criados, etc. Estos puntos, en especial el último, resultan sumamente ricos, ya que nos aproximan al ethos de aquellas personas que intentaban formar parte del servicio áulico de la corte. La veían como una fuente incalculable de mercedes y gracias, por lo que procuraban medrar e incluso entrar en competencia con sus pares, desbordando en varias ocasiones el control por parte del rey y sus oficiales.

Anuario de la Escuela de Historia Virtual - Año 11 - Nº 18 - 2020: pp. 268-271. ISSN: 1853-7049 
Finalmente, el tercer apartado nos brinda una serie de reflexiones referidas a temas variopintos, que eran intrínsecos a la vida de palacio. En este sentido, se hizo alusión a los grandes linajes que estuvieron al servicio de la reina, así como a las trayectorias individuales posteriores a la estancia en la casa de algunas figuras femeninas destacadas. Muchas de ellas se casaron e implementaron en su hogar y en la vida conyugal el aprendizaje doméstico adquirido como "criada" de la reina. Por último, se ofrece un repaso por el papel protagonizado por personas que no pertenecían a las elites del reino, tales como enanos, bufones y locos.

Un análisis integral de cada una de estas partes no solo nos da cuenta de la relevancia y solidez de la tradición historiográfica de la que es deudora su autora, sino también del utillaje metodológico por el que se optó. En este sentido, el entrecruzamiento de una vasta serie de fuentes, especialmente epistolares, permitieron reconstruir un fenómeno poco abordado por los historiadores y que se ajusta a la perspectiva adoptada. Es decir, una historia política, e incluso social y cultural, de la corte femenina española. Así, García Prieto reconstruyó este espacio gracias al estudio de la correspondencia de Antonio de la Cueva, primer marqués de Ladrada y unos de los mayordomos mayores de la reina, resguardada en British Library (Inglaterra). Asimismo, se destacan las fuentes españolas consultadas en el Archivo Histórico Nacional, en la colección Altamira del Archivo Zabálburu y el Archivo General de Simancas, en especial, la sección de Patronato. Para valerse de noticias más íntimas y personales de la vida de las infantas Isabel y Catalina, fue menester recurrir a la documentación disponible en repositorios italianos, tales como el Archivio di Stato di Firenze y el Archivio di Stato di Torino.

El entrecruzamiento riguroso de esta información, junto con los aportes de fuentes editadas y estudios históricos específicos, permitieron la culminación de un trabajo útil para abordar un mundo femenino muchas veces mediados por las fuentes masculinas. Este conocimiento indirecto no implicó que la autora no recurriera a las cartas escritas directamente por algunas de sus protagonistas, tal como las que la condesa de Paredes de Nava enviaba al secretario real Mateo Vázquez.

Asimismo, también se ofrece al lector un anexo en donde se incluyen los nombres de quienes ocuparon los puestos más importantes del servicio áulico de la casa de la reina entre 1570 y 1598. Su confección se concretó gracias al análisis de los documentos resguardados en la sección Personal del Archivo General de Palacio (España), así como al entrecruzamiento de las fuentes arriba mencionadas. Este aporte se valora positivamente, ya que permite, entre otras cosas, una identificación rápida y precisa de quienes compusieron este conjunto humano, mostrándonos una imagen dinámica del mismo a través de la variación de los nombres que tenían un cargo.

En síntesis, el aporte de García Prieto nos permite reflexionar acerca de cómo funcionaba un espacio en el que se desenvolvían tanto hombres como mujeres, pero en el que estas últimas acaparaban el mayor protagonismo, brindándonos numerosos y ricos indicios del funcionamiento de las elites españolas de fines del siglo XVI. En este sentido, resulta una contribución relevante para el estudio de las mujeres, así como del 
ejercicio del poder desde este punto de vista, y también representa un importante apéndice o caja de resonancia política de la corte de Felipe II.

Javier Hipólito Villanueva

Universidad Nacional de Salta, Argentina

javierhvillanueva@gmail.com

Para citar este artículo:

Villanueva, Javier Hipólito (2020). Reseña bibliográfica: “García Prieto, E. (2018). Una corte en femenino. Servicio áulico y carrera cortesana en tiempos de Felipe II. Madrid: Marcial Pons. 310 pp." Anuario de la Escuela de Historia Virtual, 18, 268-271. 